

\title{
Estado e desenvolvimentismo na perspectiva de Ha-Joon Chang: quando a história importa e as instituições fazem diferença
}

\author{
State and Development in Ha-Joon Chang \\ Perspective: When History matter and \\ Institutions make the difference
}

\author{
Adriano José Pereira* | Herton Castiglioni Lopes** \\ http://dx.doi.org/10.51861/ded.dmvu.2.007 \\ Recebido em 10 de agosto de 2020. Aceito em 15 de junho de 2021.
}

\begin{abstract}
Resumo
O objetivo deste texto foi destacar os aspectos fundamentais no que se refere à importância das instituições e da mudança institucional para o desenvolvimento, na perspectiva de Ha-Joon Chang. Considera-se o papel do estado enquanto agente transformador estrutural, destacando-se a relevância da sua abrangência institucional. Para Chang, o capitalismo, enquanto "sistema socioeconômico", não pode ser considerado uma "coleção de mercados". Existiria uma primazia institucional do estado em relação aos mercados, na medida em que aquele possui um caráter desenvolvimentista. Chang defende a manutenção desse caráter desenvolvimentista do estado como um recurso necessário ao emparelhamento buscado pelas economias em desenvolvimento. Neste sentido, Chang entende que as instituições promotoras do desenvolvimento decorrem de processos associados às mudanças produtivas, por isto não deveriam ser adotadas a partir de um "padrão global", em que as mesmas instituições serviriam, ao mesmo tempo, para economias desenvolvidas e em desenvolvimento.
\end{abstract}

Palavras-chave: estado; mercado; instituições; capitalismo; desenvolvimentismo.

\begin{abstract}
The purpose of this text was to highlight the fundamental aspects regarding the importance of institutions and institutional change for development, in the perspective of Ha-Joon Chang. The role of the state as a structural transforming agent is considered, highlighting the relevance of its institutional scope. For Chang, capitalism as a "socio-economic system", cannot be considered a "collection of markets". There would be an institutional primacy of the state over markets, insofar as it has a developmental character. Chang defends the maintenance of this developmental character of the state, as a necessary resource for catching up by developing economies. In this sense, Chang understands that the institutions that promote development result from processes in line with the productive changes, therefore they should not be adopted from a "global standard", in which the same institutions would serve, at the same time, for developed and developing economies.
\end{abstract}

Keywords: state; market; institutions; capitalism; developmentalism.

\footnotetext{
* Adriano José Pereira, professor associado do Departamento de Economia e Relações Internacionais da Universidade Federal de Santa María, UFSM. Av. Roraima, 1000. Cidade Universitária. Campus-UFSM. Camobi, Santa Maria-RS. CEP: $97015-900$

ORCID: 0000-0002-9467-6516.E-mail.: adrianoeconomia@ufsm.br

** Herton Castiglioni Lopes, professor adjunto da Universidade Federal da Fronteira Sul (UFFS).

Av. Jacob Reinaldo Haupenthal, 1580 - Bairro São Pedro, Cerro Largo - RS, 97900-000.

ORCID: 0000-0003-3539-1729. E-mail: herton.lopes@uffs.edu.br
} 


\section{INTRODUÇÃO}

Uma significativa parcela dos debates acerca do desenvolvimento econômico, desde os tempos de Adam Smith versus Alexander Hamilton, no cenário de final do Século XVIII e início do XIX, tem estado centrada no papel desempenhado pelo estado. A própria formação de alguns estados nacionais, em um contexto de expansão da atividade industrial e da urbanização, viria a reforçar ainda mais a necessidade de se estabelecer o escopo de ação do estado, dado a condição de desenvolvimento encontrada por cada nação. Seguindo Alexander Hamilton, List (1989) destacaria este processo, tomando como exemplo o desempenho de algumas economias europeias e dos EUA, na primeira metade do século XIX, contrastando com a economia inglesa, e contrapondo-se aos defensores do "livre mercado" como condição adequada para a promoção do desenvolvimento das economias nacionais, independentemente de sua condição estrutural.

Em grande medida, Ha-Joon Chang é um "herdeiro de List", ainda que tenha sofrido influência de outros pensadores relevantes, como Karl Marx e Joseph Schumpeter. Chang é um autor que tem dedicado parte significativa de sua obra à compreensão do desenvolvimento econômico nacional como um processo dinâmico, ambientado em um contexto histórico e, por conseguinte, que deve ser considerado a partir das singularidades das trajetórias econômicas nacionais. Para Chang, não existem instituições uniformes que servem a todos os países em um dado momento histórico. Ao contrário, as instituiçốes dos países desenvolvidos são, em grande medida, resultado do processo de desenvolvimento, e não suas promotoras.

Fazer recortes na obra de Chang consiste em uma tarefa extremamente difícil, dado que seu aporte teórico está intrinsicamente conectado ao contraponto que o autor estabelece, em grande parte de seus textos, sobretudo com o mainstream economics (com destaque para a teoria neoclássica e sua ligação com o liberalismo econômico). Por sua vez, a abordagem histórica e de análise comparativa adotada pelo autor, é fundamental para ilustrar as diferentes perspectivas de desenvolvimento, pois descarta o determinismo, o apriorismo e a atemporalidade, que são os alvos primordiais de sua crítica. Um dos destaques da crítica de Chang recai sobretudo em aspectos institucionais que, supostamente, dariam suporte ao desenvolvimento, na perspectiva do mainstream. É este último aspecto da abordagem de Chang que será destacado neste texto, com ênfase na forma como o papel do estado deve ser compreendido quando se projeta um processo de mudança estrutural e institucional favorável ao desenvolvimento.

Uma das características da perspectiva de desenvolvimento abordada por Chang, consiste justamente em compreender qual é o papel desempenhado 
pelas instituições econômicas, bem como em que medida o estado deve ser considerado um agente fundamental do processo de mudança institucional, sobretudo nas economias não desenvolvidas. Tal perspectiva acabaria levando Chang a contrapor os principais argumentos da versão institucionalista do mainstream economics, a Nova Economia Institucional (NEI). Segundo Chang, a NEI apresenta argumentos simplistas que, em grande medida, pressupõem uma aplicação atemporal das instituições econômicas, advogando que as mudanças institucionais, a partir de "instituiçôes importadas", e com ênfase nos direitos de propriedade e no livre mercado, promoveriam o desenvolvimento econômico nacional dos países não desenvolvidos. Tais argumentos da NEI serviram de base para a criação de "instituiçốes de padrão global" (Global Standard Institutions ou GSIs), que adquiriram maior evidência e tiveram forte influência nas políticas econômicas nacionais entre as décadas de 1980 e 1990, e ainda seguem tendo no presente.

No final do século XX, cada vez mais as instituições passaram a ser concebidas como parte fundamental da explicação acerca das diferenças nos desenvolvimentos econômicos nacionais. Como observa Chang (2011), as instituiçôes viraram o centro dos debates sobre desenvolvimento econômico, sobretudo a partir da crescente importância que assumiu a NEI. Considerava-se que grande parte da responsabilidade pelo fraco desempenho das economias em desenvolvimento, como no caso das latino-americanas, estaria associado a má qualidade de suas instituiçóes econômicas. Portanto, para resolver os problemas de seu desenvolvimento, as economias deveriam adotar "instituiçóes de padrão global” (GSIs), em regra seguindo uma condição de maior liberalização, sobretudo comercial, e com ênfase nos direitos de propriedade, visando uma maior garantia do cumprimento dos contratos, com crescentes restriçóes à influência do estado sobre as decisões dos agentes privados. $\mathrm{Na}$ visão do autor, a lógica por trás desse argumento, além de simplista é a-histórica, ou seja, se o que entrava o desenvolvimento econômico dos países pobres é a falta de instituiçóes eficientes, estas deveriam ser "transplantadas" a partir dos países ricos, onde já teriam demonstrado a sua eficiência.

Portanto, um dos caminhos para se entender a perspectiva analítica de Chang, acerca do papel do estado no desenvolvimento econômico nacional, consiste em verificar a forma como o autor direciona sua crítica ao mainstream economics, e ao aporte teórico adotado pelas políticas prescritas a partir das GSIs.

O objetivo principal deste texto consiste em abordar parcialmente a obra de Chang, visando tratar do papel do estado enquanto "instituição que abarca interesses coletivos” (CHANG, 2004c), contrapondo-se a lógica do 
mainstream e sua visão de que o estado, mesmo em economias não desenvolvidas, deveria limitar o seu grau de intervenção econômica seguindo os preceitos de um "estado regulador", como garantidor das "regras do jogo".

Neste ponto, é fundamental fazer alguns esclarecimentos acerca do que se entende por "estado regulador". Em razão da perspectiva institucionalista adotada neste texto, a expressão "regulador" será empregada como tendo o mesmo sentido de "neoliberal" usado por Chang (1994 e 1997a), ao referirse às políticas de "desregulamentação" adotadas nos anos 1980 e 1990. A “era da regulamentação”, entre os anos 1950-1970, se caracterizou por uma predominância de políticas desenvolvimentistas, ao passo que a "era da desregulamentação”, décadas de 1980-1990, caracterizou-se pelo predomínio das políticas neoliberais (CHANG, 1997a), em um contexto "reformista", visando uma diminuição do papel do estado na economia. Observe-se que: (...) deregulation should not be equated with the abolition of all government regulations, although which are the strictly 'necessary' regulations is another, very difficult, question. It should also be pointed out that deregulation in certain areas may require increased government regulation in other areas." (CHANG, 1997a, p. 717)

Chang (1997b e 2001) afirma que existe uma “aliança profana” entre o neoclassicismo e a tradição austríaco-libertária, reforçando que o papel do estado seria basicamente o de corrigir falhas de mercado. "Neo-Liberalism is based on an unholy alliance between Neoclassical economics, which provides the intellectual legitimacy, and the Austrian-Libertarian tradition, which provides the political rhetoric.” (CHANG, 1997b, p. 8)1Em síntese, o "estado regulador" tem como principais características constituir-se em uma instituição com ênfase burocrático-administrativa, com destaque na criação de regras e contratos, regulados, aplicados e fiscalizados a partir de agências e órgãos politicamente independentes. Seus limites de intervenção visam evitar "falhas de estado" e corrigir as "falhas de mercado", mesmo com todas as dificuldades que implicam na definição de qual é o escopo de tal intervenção. Portanto, entende-se que, mesmo adotando políticas neoliberais, a intervenção do estado na economia pressupóe um "tipo" de estado que, nesse caso, será considerado "regulador" em contraponto ao "estado desenvolvimentista”. Em suma, a partir da perspectiva de Chang, entende-se "regulador" como sinônimo de um estado com viés liberal, sobretudo no que se refere à política econômica voltado ao desenvolvimento.

Deve-se observar que Chang, ao longo de parte de sua obra, tem destacado cada vez mais a relação entre instituiçôes econômicas e desenvolvimento, tanto em âmbito nacional quanto internacional, em que o estado se apresenta como peça fundamental, independentemente do contexto ser o de um mundo cada 
vez mais globalizado; pelo contrário, para Chang, quanto mais globalizado o mundo se torna, mais necessário tem sido o papel do estado como agente do desenvolvimento em economias não desenvolvidas. Destaca-se também a perspectiva macro-institucional do autor, especificamente no que se refere ao “estado desenvolvimentista” enquanto instituição promotora do desenvolvimento, responsável pelas políticas industrial, comercial, inovativa etc. Ao mesmo tempo é importante ressaltar, como será feito na próxima seção, que existe uma crescente importância das GSIs em relação a sua influência sobre as mudanças institucionais em âmbito nacional, dado que as economias estão cada vez mais interligadas, produtivamente e institucionalmente.

$\mathrm{O}$ texto está estruturado em três seções, além desta introdução. $\mathrm{Na}$ segunda seção estão em destaque as críticas de Chang ao que ele identifica como uma visão equivocada do mainstream economics acerca do papel das instituiçóes no desenvolvimento, ressaltando o papel das GSIs e sua pauta reformista do estado, na busca de um estado "garantidor das regras do jogo" ou "regulador". Seguindo a lógica argumentativa de Chang, entende-se que a mudança institucional favorável ao desenvolvimento econômico nacional não deveria ser exógena, bem como o estado não deveria ter um papel passivo no desenvolvimento econômico nacional. A terceira seção aborda a visão desenvolvimentista de Chang, em que as transformaçôes institucionais têm papel fundamental, porque criam as bases de consolidação de uma estratégia de desenvolvimento com mudança estrutural produtiva. Por fim, são apresentadas algumas consideraçóes acerca de uma agenda de pesquisa, em curso há algum tempo, a partir da perspectiva analítica institucional de Chang sobre desenvolvimento, com destaque para as economias não desenvolvidas, o que tem destacado o autor como uma das referências do "pensamento econômico desenvolvimentista” no século XXI.

\section{GLOBAL STANDARD INSTITUTIONS (GSIS) E "ESTADO REGU- LADOR"}

Esta seção apresenta uma análise crítica de Chang em relação a visão do mainstream economics acerca do papel do estado no desenvolvimento econômico nacional, em que haveria incompatibilidade entre um "estado regulador" e a busca do desenvolvimento via estratégias de emparelhamento (catching-up), típicas de um "estado desenvolvimentista”. Em síntese, em um "estado regulador" o capitalismo é uma "economia de mercado", em que os limites de intervenção estatal visam evitar "falhas de estado" e corrigir "falhas de mercado", ao passo que, no "estado desenvolvimentista" o capitalismo é um "sistema socioeconômico", que requer uma intervenção estatal em níveis 
compatíveis com as necessidades e/ou com o padrão de desenvolvimento das economias nacionais, tanto no que se refere aos aspectos produtivos quanto aos institucionais. Destaca-se o contexto de transição do século XX para o XXI, sem negligenciar os exemplos históricos, em que as GSIs passaram a representar um conjunto de políticas para o desenvolvimento, gestadas em alguns países desenvolvidos (sobretudo nos EUA), que deveriam balizar as políticas econômicas em países não desenvolvidos, implicando em reformas institucionais visando instrumentalizar os processos de crescimento a partir de regras pré-estabelecidas.

Cabe destacar que não será tratada a perspectiva mais abrangente do estado enquanto agente do desenvolvimento, inserido em um arcabouço institucional global (global political economy, conforme Chang \& Evans (2005), e sua forma de relação com as GSIs, e, através destas, com outros estados nacionais. A perspectiva do texto compreende um escopo mais limitado, conforme expresso na introdução. No entanto, dado o avanço da globalização no final do século XX, faz-se necessário considerar a forma como os estados têm se adaptado a crescente influência das GSIs. Nesse sentido, é fundamental compreender o que são instituiçóes para Chang, para em seguida analisar a sua abrangência e relevância no que se refere ao papel do estado no desenvolvimento econômico nacional.

As instituiçốes decorrem de construções coletivas que pressupóem tomadas de decisão política para sua criação, adaptação, manutenção ou abandono. Observe-se que as decisões políticas não são pré-determinadas, mas estão condicionadas a um conjunto de fatores que envolvem indivíduos socialmente integrados visando objetivos comuns, não necessariamente objetivos que tragam o "bem comum". São incorporadas em uma estrutura organizacional que tem como uma de suas finalidades a busca de interesses comuns, socialmente referenciados, como é o caso do estado. Conforme Chang e Evans (2005), as instituições são padrões sistemáticos de expectativas compartilhadas, em que a aceitação de normas e as rotinas decorrentes de interação, têm efeitos diretos e significativos na formação das motivações e no comportamento de conjuntos de atores sociais interconectados.

À exemplo de Thorstein Veblen, um dos principais expoentes do "velho institucionalismo" (original institutional economics ou OIE), Chang admite que existem instituições que são prejudiciais ao desenvolvimento, e que a inércia, por vezes, é uma das suas características mais marcantes. Portanto, não é tarefa simples definir a priori o que são "boas" instituições, de forma padronizada, sobretudo quando se trata de GSIs. Além disso, qualquer perspectiva de implantação das GSIs demanda uma adequação do ambiente institucional existente, o que implica, em regra, em uma revisão acerca do papel 
do estado no desenvolvimento econômico nacional, bem como nas suas relações internacionais (este segundo aspecto não será abordado neste texto, como afirmado anteriormente).

Em um cenário de crise para algumas economias não desenvolvidas, como ocorreu no final do século XX, o desenvolvimento econômico nacional passou a estar cada vez mais associado a reformas visando um aumento da qualidade institucional. Tais reformas deveriam começar pela revisão do papel do estado na economia, reforçando seu enforcement action, como garantia de adoção e de funcionamento das "melhores" instituições que, por sua vez, seriam determinantes para o desenvolvimento econômico, como destacado pelos defensores das GSIs. A transformação institucional deveria começar pelo estado.

A partir do final dos anos 1980, vários acordos internacionais passaram a ser balizados a partir das GSIs. Tais instituições deveriam ser adotadas sobretudo por aqueles países que estavam passando por grandes dificuldades econômicas e precisavam de ajuda internacional. Em regra, a ajuda deveria ser obtida via Banco Mundial e Fundo Monetário Internacional (FMI), e também dependeria de adequaçóes comerciais avalizadas pela Organização Mundial do Comércio (OMC), a partir de $1995^{2}$.

Neste sentido, é importante caracterizar, resumidamente, e de acordo com Chang (2005 e 2011), do que se trata e como se aplicam as GSIs, que deveriam ser adotadas pelos países em desenvolvimento, seguindo os desenvolvidos. As GSIs se caracterizam por:

a) um sistema jurídico de direito comum, visando uma promoção de contratos com maior liberdade e com custos reduzidos;

b) um sistema produtivo baseado na propriedade privada, portanto, favorável ao aumento das privatizações;

c) um sistema financeiro baseado em um mercado de açóes, com fusóes e aquisiçóes fáceis, dando suporte a maior liberdade de transaçóes bem como as privatizações;

d) um regime de regulamentação financeira que incentive a "prudência" e a "estabilidade", incluindo um banco central politicamente independente;

e) uma governança corporativa orientada para os acionistas, que garanta que as empresas sejam administradas por seus proprietários;

f) um mercado de trabalho flexível, visando uma realocação rápida de mão-de-obra;

g) um sistema político que restringe ações arbitrárias de governantes e seus agentes (isto é, burocratas) através da descentralização do poder, bem como a minimização da discrição para agentes do setor público. 
Portanto, um "pacote" de medidas visando a substituição de instituições "ruins" por "boas", tendo como um dos focos principais a reforma do estado.

Como destaca Chang, as GSIs tendem a ser defendidas também por parte dos agentes econômicos em economias não desenvolvidas, devido ao status que as mesmas representam, a despeito do descompasso existente entre àquelas e as condiçốes locais para a sua adoção; pelo contrário, este descompasso acabaria se transformando em fator motivador das reformas do estado, visando a sua adequação a um padrão institucional supostamente favorável ao desenvolvimento, apesar da superficialidade dos exemplos dados, a partir de uma condição recente das economias desenvolvidas, sem analisar a sua história; ou seja, as GSIs representam um "pacote” de mudanças institucionais que deveriam ser adotadas pelas economias em desenvolvimento, porque seriam instituições recomendáveis a partir da condição estabelecida nas economias desenvolvidas. Nesse sentido, para Chang (2011, p. 475), os resultados acabariam demonstrando que: "GSIs are institutions that inherently favour the rich over the poor, capital over labour, and finance capital over industrial capital”, dado existir uma grande distância estrutural produtiva entre as nações desenvolvidas e as não desenvolvidas.

Claramente, a perspectiva de adoção das GSIs implicaria na redefinição do papel do estado na economia, sobretudo naqueles países em que houve forte intervenção estatal do pós-Segunda Guerra Mundial até o final da década de 1970 , e que se encontravam em crise nos anos 1980, como parte dos latino-americanos. A crise do desenvolvimentismo era considerada como um reflexo do excesso de intervenção do estado na economia. Em linhas gerais, o estado deveria abdicar da sua função de agente do desenvolvimento econômico nacional, transferindo para a inciativa privada, e em grande medida para o capital estrangeiro, o protagonismo. Nesse contexto, a ampliação das liberdades de mercado acabaria se tornando o arranjo institucional predominante, na medida em que o "estado desenvolvimentista" seria substituído por um "estado regulador", como o primeiro entrave ao desenvolvimento econômico nacional que deveria ser removido.

Apesar de não ser identificado como institucionalista, Friedman (1985) resume o que se entende por "estado regulador" (nota de rodapé 1), em uma economia em que deveriam predominar as liberdades de mercado, baseadas nas garantias de direitos de propriedade e no cumprimento dos contratos. Como se pode observar, a concepção de estado de Friedman é muito semelhante à adotada pela NEI, e que serve de base para as instituiçóes e organizações internacionais que advogavam a necessidade de adoção de GSIs, sobretudo para os países em desenvolvimento. Ao estado caberia sobretudo o enforcement action, como forma de poder de fiscalização e de sanção em 
relação ao descumprimento das "regras do jogo", como também tem argumentado a $\mathrm{NEI}^{3}$.

A criação de agências independentes (reguladoras), como uma das características principais de um estado regulador, seria considerada uma forma de "despolitização" da economia, assim como a "independência" do Banco Central. (CHANG, 1997b; 2001). Lembrando-se que a despolitização da economia não elimina os mecanismos de tomada de decisão, que são políticos, ainda que se restrinja à política macroeconômica (instrumental) por parte do governo. Esta visão liberal de despolitização da economia, a partir da redução sistemática do papel do estado no desenvolvimento, tenderia a contribuir para a concentração do poder na tomada de decisão política em razão da existência de um poder econômico previamente estabelecido. Pelo contrário, na perspectiva de Chang (1999 e 2001), quanto mais politizada for a economia, maiores seriam as chances de haver uma maior distribuição da riqueza, a partir de transformaçóes estruturais e institucionais, em função dos mecanismos de tomada de decisão política que afetam diretamente as relações econômicas em economias capitalistas. Como observa Chang (1999, p. 197): "In the end, all prices are potentially political, and there is no "scientific" rule that will tell us which prices should be "political" and which should be not." "Além disso, conforme Chang (1999), economias mais politizadas encontrariam melhores alternativas em momentos de crise, se comparadas às economias em que há concentração de poder político e econômico, onde vigoram as "leis de mercado".

O estado regulador seria caracterizado por corrigir as "falhas de mercado", dado que os mercados teriam "primazia institucional” em relação ao estado. Ao estado caberia criar mecanismos de incentivos que deveriam implicar em maiores liberdades de mercado e em uma crescente importância da iniciativa privada no processo de desenvolvimento econômico nacional. A retórica que define instituiçóes a partir de restriçôes (predominante na NEI), também defende a primazia institucional do mercado, ou seja, a necessidade de criação e imposição de restrições decorreria da impossibilidade de exercício pleno das "leis de mercado"; as falhas de mercado seriam uma exceção com necessidade de correção, limitando o papel do estado enquanto agente do desenvolvimento, com destaque para as políticas assistencialistas e macro-instrumentais de curto prazo.

Na perspectiva dos defensores das GSIs, os mecanismos de estado seriam aprisionados e utilizados em função dos grupos de interesse (rent seeking). Portanto, as "falhas de estado", a serem evitadas, seriam caracterizadas por processos, legais e ilegais, que favoreceriam interesses privados. Já as falhas de mercado, além de causarem impactos menos negativos do que as "falhas 
de estado", seriam mais facilmente corrigidas, dado que o estado seria mais "enxuto" e teria um aparato burocrático-administrativo mais profissional no sentido da eficiência da "máquina pública”. Esta concepção, como ressaltado anteriormente, estaria balizada na teoria econômica neoclássica e na adoção parcial da ideologia liberal, segundo Chang (1997b). Portanto, existiria uma aproximação significativa entre o que se entende por estado regulador e as ideias liberais predominantes entre os defensores das GSIs.

O principal problema para Chang (2001), em relação a teoria neoclássica e sua adesão parcial ao liberalismo econômico, bem como à NEI, é a falta de compreensão das relaçốes institucionais que se estabelecem entre estado e mercado. Não necessariamente as falhas de mercado (destaque-se que Chang afirma que elas existem e costumam ser importantes) devem ser corrigidas pelo estado. "(...) the same state action can be, and has been, considered an "intervention" in one society but not in another (which could be the same society at different points of time).” (CHANG, 2001, p. 4) Portanto, como definir os mecanismos e os limites da intervenção para corrigir falhas de mercado, bem como seus objetivos, a partir de regras pré-estabelecidas? Seguindo a tradição neoclássica, adotada parcialmente pela NEI, a resposta mais coerente é: a partir de regras gerais, aplicadas indistintamente. $\mathrm{Ou}$ seja, as falhas de mercado levariam à necessidade de intervenção estatal para aumentar as garantias e a eficiência dos processos econômicos, como se não houvesse nenhuma relação institucional estabelecida entre estado e mercado, em que este último, enquanto instituição capitalista, teria sido resultante de uma criação espontânea (quase natural e a-histórica).

Deve-se observar que os mercados são construções decorrentes de tomadas de decisão, portanto, são criações humanas, resultados de um conjunto de interesses variados. "(...) no market is in the end "free", as all markets have some state regulations on who can participate in which markets and on what terms." (CHANG, 2001, p. 6). Portanto, maiores liberdades de mercado, bem como um maior regramento das suas atividades, são resultantes de processos decisórios que envolvem um conjunto de diferentes perspectivas acerca de até onde o estado deve intervir, e se a intervenção deve preceder (estado desenvolvimentista, onde o estado tem primazia, como será visto na próxima seção) ou suceder (estado regulador, onde a primazia é do mercado) as "falhas de mercado".

Por sua vez, a função do estado como "regulador”, acabaria ampliando a importância dos mercados para o desenvolvimento econômico nacional. Para tanto, as reformas institucionais passariam a ser consideradas pré-requisitos fundamentais da busca pelo desenvolvimento. Neste cenário, as GSIs passariam a ganhar cada vez mais importância e requerer uma ação reforma- 
dora do estado e uma nova configuração das suas relaçôes institucionais, em âmbito interno e internacional. Nesse contexto, a reforma do estado seria necessária para criar um ambiente favorável a adoção das "boas" instituiçôes. Assim, a qualidade institucional passaria a ser considerada um pré-requisito básico do desenvolvimento, e os parâmetros para definir tal qualidade seriam definidos a partir de economias desenvolvidas, com destaque para os EUA.

Chang (2004a) observa que as "boas" instituiçôes, existentes nos países desenvolvidos, e que são recomendadas aos países em desenvolvimento, não são causas, mas resultantes do próprio processo de desenvolvimento. Nesse sentido, há um descompasso em relação aos efeitos que estas "instituições boas" podem gerar, quando não são considerados as singularidades das trajetórias das economias nacionais.

Para Chang (2011), além de problemas de atemporalidade, no que se refere as GSIs, existem problemas teóricos com o discurso dominante sobre a relação existente entre instituiçóes e desenvolvimento econômico. Primeiramente, cabe destacar que a relação de causalidade, que vai de instituições "melhores" promovem mais desenvolvimento, é simplista e linear, além de não ser compatível com a experiência histórica das nações; não há primazia causal das instituições em relação ao desenvolvimento e a mudança estrutural produtiva das economias. Como ressalta e exemplifica o autor: "(...) economic development brings about cultural/institutional changes, as much as the latter changes bring about economic development. For example, industrialization makes people more 'rational' and 'disciplined's." (CHANG, 2011, p. 492) Em síntese, conforme Chang (2011, p. 482): “(...) mainstream institutional theories wrongly see the relationship between institutions and economic development as linear and uniform across time and space."

Como observa Chang (2011, p. 476), a relação causal, no que se refere ao desenvolvimento econômico, tem diferentes formas de ocorrência, que não estão condicionadas a existência prévia de instituiçôes "melhores":

Economic development changes institutions through a number of channels. First, increased wealth due to growth may create higher demands for higherquality institutions. Second, greater wealth also makes better institutions more affordable. Institutions are costly to establish and run, and the higher their quality the more 'expensive' they become (see below). Third, economic development creates new agents of change, demanding new institutions.

E acrescenta: "Indeed, there is quite a lot of historical evidence to suggest that the causality may be stronger in the latter direction (economic development improving institutions) than in the former (better institutions promoting economic development).” (CHANG, 2011, p. 476). 
Do ponto de vista histórico, a argumentação teórica de que instituições "melhores" são previamente necessárias para o desenvolvimento, é ainda mais frágil e carente de evidências. Como ressalta Chang (2004ab, 2009ab), com uma série de exemplos de economias nacionais desenvolvidas, as instituiçôes foram criadas e aperfeiçoadas conforme estas economias foram se desenvolvendo, em regra com forte intervenção estatal e com políticas protecionistas, inclusive, em muitos casos, desrespeitando direitos de propriedade em âmbito internacional. Em síntese, como ressalta Chang, a relação entre desenvolvimento e instituiçôes é dinâmica, por isto é tão importante compreender que os processos de mudança estrutural e institucional se dão de forma conjunta.

Chang (2001; 2004abc; 2009b; 2011) questiona em que medida instituições "liberais" são favoráveis ao desenvolvimento econômico, dado que as naçôes (e suas empresas) se encontram em diferentes condiçốes de competição internacional; nesse sentido, maior liberdade, ainda que com garantias de direitos de propriedade, papel fundamental de um estado regulador, não representa condição favorável a melhoria do desempenho econômico, apenas tende a favorecer aqueles que já se encontram em uma situação avançada do ponto de vista da capacidade competitiva.

Chang (2011) elenca um conjunto de autores que justamente entendem que maiores liberdades de mercado não devem ser uma regra adotada por todos em qualquer momento ou circunstância. ${ }^{6}$ Além disso, em regra, as maiores liberdades de mercado costumam criar dificuldades em se tratando da adoção de estratégias de desenvolvimento, como será visto na próxima seção.

These examples show that the very definition of a free market depends on whether an observer accepts the political and ethical values embodied in the institutions that gird the market. In other words, different people with different values will see different degrees of freedom in the same market. If it is impossible to objectively define the boundary of the free market, we cannot know which institutional arrangements will maximize economic freedom (whatever its impact on economic growth and development may be). (CHANG, 2011, p. 478).

Chang (2011) questiona as evidências empíricas acerca da relação entre GSIs e crescimento econômico, argumentando que o fato de existir correlação entre instituiçôes de cunho liberal e crescimento econômico, não estabelece, a priori, o sentido direcional desta relação; nem mesmo se ela se sustenta no longo prazo, ou se levaria a uma mudança estrutural favorável ao desenvolvimento. Cita como exemplo negativo o caso de países que têm taxas de crescimento em anos sucessivos, baseadas em maiores liberdades comerciais e na exportação de produtos básicos (com destaque para commodities primá- 
rias). Destaca também que a "qualidade institucional” é quantificada a partir de índices que levam em consideração julgamentos viesados, baseados, em grande medida, em instituiçốes de economias desenvolvidas. " "(...) reality is often stranger than fiction and therefore our theories need to be more richly informed by real-world experiences - both history and modern-day events." (CHANG, 2011, p. 494).

Portanto, um dos problemas das GSIs consistiria na ausência de contextualização delas mesmas, ou seja, não necessariamente são políticas inadequadas, mas não costumam ser eficientes quando adotadas de forma padronizada, independente do estágio de desenvolvimento das economias. Ressalva, aliás, que List (1989) havia feito no século XIX, quando questionou a política de liberalização inglesa. List (1989) defendia uma redução do protecionismo a medida em que as demais naçôes da Europa ocidental, em relação à Inglaterra, pudessem atingir um nível mínimo de competitividade internacional no que se refere a produção industrial; antes disso, a indústria deveria ser considerada "nascente", portanto, com necessidade de proteção para desenvolver-se. Chang (2004a; 2009b), atualiza e contextualiza grande parte dos argumentos de List, tanto no que se refere as estratégias de desenvolvimento quanto no que diz respeito a forma de inserção das economias no comércio internacional. Portanto, não se trata de uma rejeição plena das GSIs, mas da negação da eficiência da sua padronização, dado ser este um argumento apriorista e a-histórico, e pretensamente despolitizado, que não prioriza a condição produtiva, tecnológica, financeira e comercial das naçóes não desenvolvidas.

Em relação a uma maior garantia de direitos de propriedade, primeiramente é importante destacar que nem sempre há clareza acerca do que é interesse público em relação aos interesses privados ${ }^{8}$. $\mathrm{Na}$ tradição liberal, que é tomada como válida pela teoria neoclássica e baliza as GSIs, a busca do interesse privado levaria a melhoria do uso dos fatores (alocação e distribuição), o que resultaria em benefício econômico coletivo; ao estado caberia, sempre que necessário, corrigir as falhas de mercado decorrentes de tais exercícios de liberdades. Por sua vez, Chang (2011) entende que a propriedade estatal, ou sob o controle do estado, muitas vezes é fundamental para promover o desenvolvimento (cita exemplos da China, de Singapura etc.)_.In other words, a high degree of state ownership may in some cases be exactly what enables the country to offer strong protection of private property rights." (CHANG, 2011, p. 480-1) Portanto, na visão do autor, a criação, e sobretudo a manutenção de direitos de propriedade privados, não constituem garantias de um melhor desempenho econômico. Inclusive a institucionalização de direitos de propriedade privados, por vezes representam a manutenção do status 
quo, dificultando quaisquer tentativas de mudança estrutural favorável, por exemplo, ao emparelhamento tecnológico das naçôes. Elevados níveis de proteção, por exemplo, em relação aos direitos de propriedade sobre inovação, justificados pelos custos e riscos inerentes ao processo inovativo (bastante utilizados na indústria farmacêutica, por exemplo), por vezes trazem benefício líquido a um país rico (para suas grandes corporaçôes) podendo ser prejudicial para países em desenvolvimento, reforçando a dependência tecnológica e aumentando as desigualdades entre as naçóes. ${ }^{9}$

Cabe destacar que existe vantagens por parte dos países em desenvolvimento na adoção de instituiçóes já existentes, devendo-se levar em conta a capacidade de adaptação no país de destino bem como a "dosagem" na adoção destas instituiçôes (CHANG, 2007). Como observa Chang (2007, p. 14): "Institutional development, especially if it is conceived as a means to promote economic development, is an area where finding a neat solution that applies to every country is simply impossible.” Faz-se necessário compreender a realidade econômica nacional e como as instituiçóes existentes operam, favorecendo ou dificultando o desenvolvimento. "In the same way in which they can import better technologies without having to pay the full cost of developing them, late-comer countries can import superior institutions without having to pay for their development." E acrescenta: "We need to look at the causality in the other direction as well, if we are to have a full understanding of how institutions and economic development interact with each other and give the right policy advice.” (2011, p. 477).

Em síntese, a adoção das GSIs demandaria um ambiente institucional compatível com as características de um estado regulador, ou seja, em que o estado não é o agente central do desenvolvimento, mas uma organização burocrático-administrativa, que visa sobretudo o estabelecimento e o cumprimento de regras e contratos, com agências e órgãos independentes (despolitizados). O estado deveria limitar a sua atuação para tentar evitar "falhas de estado" e corrigir "falhas de mercado", ou seja, o mercado tem primazia institucional, portanto, nestas circunstâncias, capitalismo seria sinônimo de “economia de mercado", em que a política econômica deveria estabelecer um ambiente favorável para a criação de mecanismos de incentivo produtivo via mercado, como tem sido defendido pela “aliança” entre neoclássicos e liberais.

\section{ESTADO E INSTITUIÇÕES PROMOTORAS DO DESENVOL- VIMENTO}

Em uma situação em que existe primazia dos mercados, visão liberal que é compartilhada pelos neoclássicos e pela NEI, um estado ideal serviria para 
corrigir falhas de mercado, considerando-se que, "no início haviam mercados" ${ }^{10}$ e que a necessidade de regular as trocas, para aumentar a eficiência e melhorar o desempenho das economias, faria com que os mecanismos de estado (e o próprio estado) se estabelecessem. Chang (2001) contesta esta interpretação, buscando em exemplos históricos as evidências de que os mercados são criaçóes decorrentes da organização coletiva e da própria formação dos estados nacionais. ${ }^{11}$

Mercados são apenas um dos mecanismos institucionais que compõem uma economia capitalista, não podendo ser vistos como algo "natural", e sim como uma criação humana que tem sido, ao longo do tempo, suscetível a necessárias intervençốes estatais, inclusive no que se refere a sua formação ${ }^{12}$. Mercados seriam, fundamentalmente, "construções políticas”. Em suma, para Chang (1997b; 1999), não existem “mercados livres”, portanto, o estado sempre terá algum papel na economia. A questão central é saber qual seria o papel institucional do estado em relação ao desenvolvimento econômico nacional, na medida em que este processo nâo decorre de uma economia de livre mercado.

Nesse sentido, é importante destacar que os mercados são resultantes de interação institucional, e não instituiçôes que se estabelecem para serem administradas após o seu surgimento, quando apareceria a necessidade de gerenciar as suas falhas. Este é um aspecto fundamental, que diferencia um estado desenvolvimentista de um estado regulador, como será visto. Deve-se ressaltar que o que se considera como intervenção do estado na economia pode variar de uma sociedade para outra, bem como em uma mesma sociedade em diferentes momentos históricos. (CHANG, 1997b)

Em conjunto, o aparato teórico-metodológico, a perspectiva históricocomparativa, a contraposição ao mainstream, e a visão estruturalista e evolucionista de Chang, dão suporte às suas proposiçóes desenvolvimentistas, servindo como uma moldura para definir as funçôes institucionais que o estado possui no que se refere ao desenvolvimento, ou seja, servem de base de sustentação da "economia política institucionalista" (institutional policy economy ou IPE) do autor. A IPE proposta por Chang (1997b; 2011) seria caracterizada por alguns aspectos fundamentais. Haveria a necessidade de compreender as relaçôes entre mercado, estado e outras instituições, considerando diferentes perspectivas teórico-analíticas acerca do papel do estado e do mercado no desenvolvimento. Além disso, destaca que o capitalismo é um "sistema socioeconômico", que não pode ser considerado, de maneira simplista, como sinônimo de "economia de mercado" (ou como uma "coleção de mercados", conforme Chang (1997b). Tais características tornam a criação, bem como a mudança institucional, um processo complexo e sem resultados previsíveis. 
Começa-se pela ideia de que o estado é uma instituição, integrado por um conjunto de outras instituições, as quais se encontram em constante interação. "The state is de-composed into many of its constituent institutions - the political system, the bureaucracy, the fiscal system, the welfare state, the institutions for industrial policy, and so on.” (CHANG, 2007, p. 4) Esta questão é um ponto de partida necessário para analisar o "estado desenvolvimentista”, sobretudo porque Chang entende que o estado tem funções fundamentais na promoção do desenvolvimento econômico, objetivo para o qual são criadas e estabelecidas instituiçốes ao longo do tempo. Portanto, não se trata da incorporação de "boas" instituições consolidadas em algumas economias, mas da capacidade de endogeinização dos processos constitutivos de instituições em um contexto nacional, ainda que tais processos sofram influências externas.

The capitalist system is made up of a range of institutions, including the markets as institutions of exchange, the firms as institutions of production, and the state as the creator and regulator of the institutions governing their relationships (while itself being a political institution), as well as other informal institutions such as social convention. (CHANG, 2001, p. 8).

Para Chang e Andreoni (2019), o mainstream institucional (NEI) confunde forma com função, ou seja, não basta identificar, a partir das economias desenvolvidas, quais as melhores formas institucionais, é preciso compreender quais funçôes as instituiçôes cumprem e como elas se estabeleceram. ${ }^{13}$

Nesse sentido, para além de regular as atividades econômicas, condição necessária em uma economia baseada em trocas, o estado desenvolvimentista deveria estabelecer-se a partir de um aparato institucional criado com vistas ao desenvolvimento, em interação com as demais instituiçóes (mercados, empresas etc) que são fundamentais em uma economia capitalista. Lembrando-se que o próprio estado é uma instituição composta por um conjunto de outras instituições.

Dado que as instituiçóes podem servir a várias funçóes, é correto caracterizar o estado como uma "instituição", que é composta por outras instituiçôes, a partir de suas multifuncionalidades. Além disso, Chang destaca que diferentes instituições podem ter uma mesma função, ou até mesmo diferentes funções, em se tratando de lugares e momentos distintos. É nesse sentido que instituiçốes desenvolvimentistas podem, pelo menos aparentemente, não serem adequadas em economias desenvolvidas, ao passo que seriam fundamentais em economias em desenvolvimento. Portanto, é preciso considerar a história, a trajetória e a singularidade das economias nacionais para se compreender as razóes da existência e a importância de um estado desenvolvimentista. 
Além disso, para Chang e Evans (2005), o estado desenvolvimentista é uma instituição ameaçada pelo avanço da globalização, mas sobretudo por questóes nacionais internas, em que existe uma adesão às políticas com orientações voltadas a redefinição de seu papel, com destaque para a primazia institucional do mercado, com forte viés liberal, como destacado na seção anterior. Para os autores, esta "visão nacional" também demonstra a falta de compreensão do processo de formação das instituições e de como elas afetam o desenvolvimento, ou seja, o estado regulador não se constitui em um "modelo" onde o interesse público se sobrepóe aos interesses privados, pelo contrário, a forma como se estabelecem os mecanismos de estado, a partir das reformas, decorrem de objetivos concretos dos agentes econômicos; a "visão nacional" não necessariamente é "nacionalista", e nem mesmo tende a ser desenvolvimentista. Isto posto: "Depending on how people interpret their 'tradition', which aspects of it they choose to highlight, and which interpretation wins in political and ideological battles, a country could evolve into very different directions.” (CHANG, 2011, p. 492).

Como destaca Chang (2011, p. 489-90):

(...) human beings are products of existing institutions, which are in turn a mixture of deliberate choices made by agents of yesteryears and the institutions that had existed prior to those agents and at least partially formed them (this is what Chang and Evans, 2005, call the 'constitutive' role of institutions $\left.{ }^{14}\right)$. (...) In this sense, the path-dependence in the process of institutional evolution operates at a more fundamental level than we normally think.

Nesse sentido, a mudança institucional é um processo complexo e multidirecional (CHANG \& EVANS, 2005). Daí a crítica feita ao mainstream economics e a algumas organizaçóes internacionais (FMI, BID, OMC etc) de que não se pode entender que uma instituição é "mono-tarefa" (monotasking), servindo a um único propósito específico para o qual ela foi criada. Abordagens institucionais "estreitas" ou restritas, levam a conclusóes enganosas sobre dinâmica institucional, com elevado risco de determinismo nas relaçóes de causa e efeito, distanciando a perspectiva teórica da realidade histórica.

Além disso, como observa Chang (2007, p. 6): "Institutions do not function in a vacuum but interact with other institutions." Portanto, "importar” instituiçóes pode trazer ainda mais dificuldades para o desenvolvimento, dado a incompatibilidade institucional com as instituiçôes domésticas, o que tende a tornar a situação ainda mais problemática em relação as instituiçôes informais do país de destino. Nesse sentido, o estado, enquanto criação histórica, é uma instituição composta a partir de estratégias de desenvolvimento, porque também exerce o papel de coordenador/articulador institucional ${ }^{15}$. 
Segundo Chang (2007), as condições impostas pelo FMI, Banco Mundial e OMC, para obtenção de recursos e condições favoráveis de negociação junto a estas organizaçóes, a partir da crise financeira que se estabeleceu em vários países ao longo da década de 1980, estavam centradas na adoção de instituiçôes consolidadas nos países desenvolvidos, que deveriam ser adotadas pelos países em desenvolvimento, como se as "melhores" instituiçóes funcionassem como mecanismos de desenvolvimento com resultados automáticos.

É necessário compreender que existe um processo dinâmico no que se refere às mudanças institucionais, que em regra decorre da capacidade de inovar de cada país bem como das condiçốes necessárias para aprender com as economias avançadas. Portanto, não se trata de uma visão negacionista, $a$ priori, em relação as instituiçôes originadas nos países desenvolvidos, mas da necessidade de compreender em que medida tais instituiçôes são resultantes e não causas do desenvolvimento, ou seja, faz-se necessário compreender o processo de mudança institucional.

Na perspectiva de Chang (1994; 1999; 2004bc), o desenvolvimento econômico resulta de mudanças estruturais, de caráter tecnológico e institucional, que deveriam ser promovidas em larga escala. Para que tais mudanças ocorram, o estado desenvolvimentista deveria intervir no sentido de cumprir algumas funções fundamentais. Enquanto "coordenador da mudança", na medida em que reuniria interesses público e privados, o estado realizaria e/ou direcionaria atividades que o setor privado não realizaria a partir das relações de mercado, inclusive no que se refere ao financiamento público visando o investimento privado em atividades fundamentais para o desenvolvimento econômico nacional. $\mathrm{O}$ estado desenvolvimentista também deveria ter um papel "empreendedor", provendo uma "visão de futuro", criando, desenvolvendo e adaptando instituições, que favorecessem o ambiente de tomada de decisão e criassem incentivos aos agentes privados, visando aumentar a adesâo às políticas de desenvolvimento (por exemplo, política industrial, tecnológica e comercial integradas). O estado seria o único agente capaz de representar os interesses de toda a sociedade, e nesse sentido deveria ter como função elaborar estratégias de desenvolvimento, coordenando ações ao longo do tempo, em uma "visão de futuro" associada ao acompanhamento e a realização de ações em direção aos objetivos de longo prazo. ${ }^{16}$ Por isto Chang entende ser necessário que o "estado empreendedor" lidade institucional" compatível com a "visão de futuro". "In this process of institution building, the state is not merely responding to change but also leading them (...)" (CHANG, 2004b, p. 55).

$\mathrm{Na}$ condição de "empreendedor", o estado desenvolvimentista conduziria o processo de "construção institucional”, necessário para viabilizar o 
desenvolvimento econômico nacional a partir da aglutinação de interesses público e privados. No entanto, Chang (1999, p. 196) observa que: “(...) the uncertainty and the conflicts inherent in the process of institution building mean that, although necessary, institution building by the state cannot be expected to produce 'optimal' outcomes." Prover uma "visão de futuro" ou "empreendedora”, demonstra que o estado é um agente do desenvolvimento econômico nacional que "coordena as mudanças", em que os interesses privados não se sobrepõem ao interesse público, muito menos ao "bem estar social”. Situação que leva a um outro papel fundamental do estado, o de "gestor de conflitos".

Como um "gestor de conflitos", sobretudo ao longo do processo de mudança estrutural, caberia ao estado atuar como um aglutinador de interesses coletivos, função que não pode ser exercida pelos mercados, em razão de serem espaços predominantemente de competição.

Em uma ação combinada, como "empreendedor" e "gestor de conflitos", o estado exerceria a capacidade de coordenação em uma estratégia de desenvolvimento, e é nesse sentido que é considerada a sua capacidade de atuar como uma "instituição" que comporta um conjunto de outras instituiçóes necessárias ao desenvolvimento. Observe-se que as diferentes formas de ação, que compreendem o papel do estado desenvolvimentista, devem ser consideradas em conjunto, dado que existem mecanismos de autorreforço, que contribuem para a consolidação de instituições favoráveis ao desenvolvimento.

A partir do conceito de "capacidades sociais" de Moses Abramovitz, Chang e Andreoni (2019) destacam um conjunto de "instituiçóes-chave" em um processo de industrialização, com caráter desenvolvimentista, tais como as "instituições de produção", que foram sendo desenvolvidas a partir dos "modelos" taylorista, fordista e toyotista, como arranjos fundamentais para o desenvolvimento produtivo a partir do setor industrial. Por sua vez, as "instituiçốes de desenvolvimento de capacidades produtivas" seriam inerentes ao funcionamento interno das corporaçóes (do Taylorismo às cadeias globais de valor), ainda que decorram de condicionantes criados a partir de políticas públicas, que caracterizam a capacidade empresarial de absorção e adequação às mudanças a partir dos “modelos”. Portanto, são instituiçóes inerentes às corporaçôes, mas que também possuem um caráter intermediário, em razão do ambiente institucional. As "instituições de governança corporativa” cumprem a função de operar como mecanismos de cooperação, entre proprietários (acionistas) e trabalhadores, como forma de estabelecer objetivos comuns a partir de relações de produção. Já as "instituiçôes de financiamento industrial” proporcionariam condiçóes favoráveis à execução de projetos de longo prazo, possibilitando a realização de investimentos pro- 
dutivos a partir de bancos comerciais, mas sobretudo de bancos públicos. As “instituições de mudança e reestruturação industrial” visam criar condições favoráveis às mudanças inerentes a estrutura produtiva industrial, próprias do capitalismo, incluindo a necessidade de realocação de trabalhadores, entre diferentes setores/atividades produtivas. Por fim, as "instituições de gestão macroeconômica para a industrialização” teriam o papel de prover uma política econômica, utilizando-se favoravelmente de preços, como juros e câmbio, orientada para uma visão de longo prazo, além de buscar garantir a estabilidade macroeconômica em seu conjunto (contas públicas, inflação etc.), inclusive no que se refere às açôes anticíclicas. Em conjunto, tais instituiçôes compreenderiam um escopo de abrangência fundamental para uma estratégia desenvolvimentista centrada no setor industrial.

Por um lado, organizações vinculadas ao estado podem ser tratadas como atores (ou instrumentos) do desenvolvimento, em uma perspectiva institucionalista mais ampla como a de Chang (2011), Chang e Evans (2005) e Chang e Andreoni (2019), ao passo que, para os indivíduos (cidadãos), tais organizaçôes podem se apresentar como instituiçốes. ${ }^{18}$ Nesse sentido, o estado pode ser compreendido como uma instituição composta por um conjunto de atores que, dependendo da perspectiva, são também instituiçôes. As ações coordenadas fazem com que este conjunto de instituiçôes criem condiçóes e um ambiente favorável ao desenvolvimento. Portanto, fica evidente que existe uma incompatibilidade institucional entre o estado regulador, e seu viés liberal, e uma estratégia de desenvolvimento em que o estado teria um papel fundamental, em uma perspectiva desenvolvimentista.

Inclusive no que se refere aos "objetivos do milênio" (ONU), Chang (2009) entende que há uma perspectiva mais assistencialista do que propriamente uma definição de ações concretas visando o desenvolvimento das nações pobres, diferenciando o estado desenvolvimentista de um "estado assistencialista”. Além disso, na visão do autor, tais “objetivos” não visam promover mudanças estruturais que gerem desenvolvimento, e sim reforçar um quadro de especialização baseado em vantagens comparativas estáticas (ricardianas $)^{19}$. Sem mudança na estrutura produtiva, associada a endogeneização de inovaçóes tecnológicas e institucionais (tecnologias físicas e sociais), ou seja, sem o desenvolvimento de capacitação tecnológica e institucional e das "capacidades sociais", não há desenvolvimento. “(...) it is not what one has but how one has got it that determines whether a country is developed or not." (CHANG, 2009, p. 5).

O estado desenvolvimentista, ao mesmo tempo em que se utiliza das instituiçóes vigentes, também tem capacidade de promover a mudança institucional em âmbito nacional, levando-se em consideração o contexto interna- 
cional. Para tanto, utiliza-se de um aparato institucional incompatível com um estado limitado a adoção dos preceitos das GSIs, que estão baseados no aporte teórico do mainstream economics institucionalista, vinculado parcialmente ao neoclassicismo e às ideias liberais.

A importação indiscriminada de instituições, incompatíveis com a estrutura produtiva e organizacional dos países em desenvolvimento, acabaria trazendo mais empecilhos do que facilidades ao desenvolvimento econômico nacional, o que é um dado histórico. Mesmo para sua adaptação, haveria a necessidade de uma intervenção estatal incompatível com um estado regulador. Nesse sentido, um estado desenvolvimentista seria mais adequado, no que se refere a adoção de uma estratégia de desenvolvimento econômico nacional, ainda que o ambiente institucional seja fortemente influenciado pelas GSIs. Como empreendedor, gestor de conflitos e coordenador da mudança, o estado desenvolvimentista continuaria sendo o agente central do desenvolvimento em economias não desenvolvidas, mesmo (e sobretudo) em um contexto de crescente globalização.

Em síntese, em uma estratégia desenvolvimentista, as ações do estado importam e as instituiçóes fazem a diferença no desenvolvimento econômico nacional. Portanto, um estado desenvolvimentista é incompatível com uma adoção irrestrita das GSIs, como "regras do jogo" fundamentais na busca do desenvolvimento. O que também foi válido para as "GSIs do passado", e provavelmente será válido para as "GSIs do futuro", dado que as desigualdades do desenvolvimento são uma característica inerente ao "sistema socioeconômico" capitalista.

\section{CONSIDERAÇÕES FINAIS}

A forma como Chang aborda as relações existentes entre instituiçóes e desenvolvimento tem sido de extrema importância sobretudo para aqueles que buscam compreender as dificuldades pelas quais vêm passando as economias não desenvolvidas atualmente. $\mathrm{O}$ autor tem se caracterizado por uma visão histórica no que se refere a compreensão da mudança institucional e de como esta mudança está associada as transformaçóes produtivas e tecnológicas. Deve-se observar que apesar da sua preocupação histórica com os diversos casos de países e suas particularidades, em momento algum o autor negligencia os aspectos teórico-conceituais e metodológicos, que norteiam as suas análises acerca do desenvolvimento, que têm sido realizadas a partir de uma base científica alternativa ao mainstream economics institucional. Nesse processo, Chang se associa a visão de importantes pensadores econômicos considerados heterodoxos, inclusive do ponto de vista institucional. 
São várias as características marcantes da obra de Ha-Joon Chang que têm sido cada vez mais compartilhadas por outros pesquisadores mundo afora. O objetivo central deste texto foi destacar os aspectos fundamentais no que se refere a importância das instituiçóes e da mudança institucional, em se tratando especificamente do papel do estado enquanto agente transformador estrutural, e considerando-se os aspectos mais relevantes da sua abrangência institucional na busca do desenvolvimento econômico. Portanto, a perspectiva analítica de Chang não separa as mudanças estruturais produtivas das mudanças institucionais, mas visa estabelecer uma relação causal dinâmica, em que as estruturas produtivas demandam instituiçôes compatíveis.

Trata-se de um autor cuja obra compreende um grau de complexidade elevado, e qualquer fragmentação de seu pensamento só é viável para fins puramente analíticos e, em parte, especulativos. No entanto, por paradoxal que pareça, abordar um aspecto mais específico da obra de Chang permite um maior aprofundamento e compreensão dos demais aspectos do seu pensamento econômico sobre desenvolvimento, principalmente no que se refere a sua Economia Política Institucional. De certa forma, algumas pesquisas acerca do desenvolvimento econômico em economias não desenvolvidas têm encontrado em Chang uma importante referência para compreender tanto as diferentes trajetórias das economias bem como os motivos das suas singularidades. Ao destacar a importância do estado como agente do desenvolvimento econômico, Chang argumenta a favor de seu caráter desenvolvimentista, como um recurso necessário ao emparelhamento buscado pelas economias em desenvolvimento, a partir de argumentos teóricos sempre baseados em fatos empíricos.

Por fim, cabe destacar que Chang tem consolidado uma agenda de pesquisa, com aporte teórico-conceitual e analítico-metodológico que destaca a necessidade de compreensão do desenvolvimento como um processo histórico e dinâmico, inclusive do ponto de vista institucional. Nesse sentido, tem sido um autor fundamental no resgate de visóes econômicas que marcaram a história dos debates sobre desenvolvimento, consolidando-se como um importante elo de ligação entre autores dos séculos XIX e XX e a formação de pesquisadores no século XXI. 


\section{Notas}

1 Segundo Friedman (1985, p. 33), um dos principais expoentes do liberalismo econômico na segunda metade do século XX, o "papel do governo numa sociedade livre, "(...) é o de fazer alguma coisa que o mercado não faz por si só, isto é, determinar, arbitrar e pôr em vigor as regras do jogo."

2 Cabe observar que os acordos (com destaque para as "rodadas") firmados no âmbito do GATT (General Agreement on Tariffes and Trade, criado em 1947), antecessor da OMC, já tinham um viés pró-liberalização comercial.

3 Para um maior detalhamento acerca do papel de "jogadores" e das funções das "regras do jogo", bem como de sua adoção, ver North (1990 e 1991) e Williamson (1989). Apesar de não ser um dos objetivos deste texto, cabe ressaltar que Chang, influenciado pelo "velho institucionalismo" e por seus "herdeiros", também contrapõe-se a visão da NEl no que se refere a indivíduos que tomam decisões em um determinado contexto institucional, portanto, em que uma maior clareza e definição de regras são favoráveis a diminuição de incertezas inerentes à tomada de decisão, onde as "boas" instituições seriam aquelas que permitiriam resultados mais eficientes a partir de decisões individuais em ambientes em que haveria menor incerteza (ou maiores garantias) em relação às transações.

$4 \mathrm{O}$ autor cita como exemplos dois preços fundamentais, salários e taxa de juros, que são definidos politicamente, e a muito tempo, em várias economias.

5 Ver os exemplos de Japão e Alemanha em "Maus samaritanos" (CHANG, 2009b), bem como de outros países em "Chutando a escada" (CHANG, 2004a).

6 "On top of that, there are many non-neoclassical economic theories that say that free markets may be less good at generating growth than markets that are, depending on the circumstances, protected, regulated, managed, or monopolized - such as the infant industry argument of Alexander Hamilton (1789) and Friedrich List (1841; List, 1885), Joseph Schumpeter's (1987) theory of innovation, and the more recent literature on the economics of technology (see Freeman, 1982; Nelson and Winter, 1982; Lundvall, 1992; Lall and Teubal, 1998; Kim and Nelson, 2000; Cimoli et al., 2009)." (CHANG, 2011, p. 479)

7 "Moreover, many of these indexes are based on surveys among (especially foreign) businessmen and experts (e.g., academics or financial analysts), many of whom were trained in the USA." (CHANG, 2011, p. 484)

8 Chang (1997a) esclarece que a ideia de "interesse público" é originária da teoria neoclássica, e é por vezes difícil de ser compreendida, sobretudo em função da existência de instituições "mistas", levando alguns autores a preferirem a adoção de ideias mais amplas, como a de "bem estar social". Neste texto, por simplificação, vamos adotar a ideia de "interesse público" apenas como contraponto ao "interesse privado".

9 O caso das patentes da indústria farmacêutica é um exemplo de que o interesse privado, em muitos casos, se sobrepõe ao interesse público e aumenta as desigualdades entre as nações. Nos neoschumpeterianos, por exemplo, direitos de propriedade bem definidos podem agir no sentido de bloquear o desenvolvimento de algumas nações, dado que impedem a apropriação tecnológica pelos países menos desenvolvidos, dificultando o processo de catching up (FREEMAN e PEREZ, 1988, e PEREZ, 2004)

10 Afirmação feita por Oliver Willliamson (apud CHANG, 2001, p. 9), um dos principais expoentes da NEl.

11 Em tempos mais recentes existem vários exemplos de "criação de mercados" em que o estado foi precursor, como por exemplo, com grandes investimentos baseados em P\&D e inovação, em que só mais tarde alguns mercados na área das tecnologias da comunicação e da informação (TICs) foram organizados. Mesmo em um contexto de "desregulamentação", como o dos anos 1980 e 1990, a ação do estado implica na "criação de mercados" (CHANG, 1997a), como ficou evidente nos casos de privatizações ocorridas em vários países.

12 Os mercados não podem preceder as instituições porque não é possível entender qualquer tipo de interação social sem a existência prévia de instituições. Para Hodgson (2007), por exemplo, o funcionamento dos mercados (e os mecanismos de preços), mesmo na teoria neoclássica, demandam interações sociais, com estruturas e fenômenos que não podem ser reduzidos inteiramente a indivíduos isolados.

13 Por exemplo, democracia liberal, judiciário independente, banco central independente etc., são formas institucionais resultantes de processos de desenvolvimento em alguns países, mas quais as funções que dão condições ao estabelecimento destas formas, na busca do desenvolvimento? Não há uma única resposta para esta questão na perspectiva de Chang.

14 Chang e Evans (2005) destacam a proximidade deste conceito em relação a OIE, com destaque para Geoffrey Hodgson. Para maiores detalhes sobre a ideia de "reconstituive downward effects", ver Hodgson (2019). 


\begin{abstract}
15 Mesmo Douglass North, apesar de enfatizar o papel do mercado na performance das nações e ser reconhecido como pertencente ao núcleo teórico da NEl, admite que instituições não podem ser transplantadas de um país para outro porque encontram restrições nos elementos cognitivos individuais e coletivos que interagem com as regras do jogo (NORTH, 2005; NORTH, WALLIS \& WEINGAST, 2009)

16 Nesse ponto é fundamental destacar que o autor diferencia as estratégias de desenvolvimento, como política de estado, da operacionalização dos processos econômicos como ações de governo. Por isso o estado desenvolvimentista é um "empreendedor", e não apenas um executor de políticas macro-instrumentais e de curto prazo.

17 Tal proposição de Estado empreendedor tem sido foco de discussão de Mazzucato (2014). A partir de uma perspectiva teórica keynesiana e schumpeteriana a autora demonstra que cabe ao estado ações efetivas para promoção do desenvolvimento (Estado Arrojado). Cabe destacar que "estado empreendedor" não é sinônimo de estado produtor.

18 Em um contexto internacional, o estado nacional também pode ser analisado enquanto ator, dado que o ambiente institucional é ampliado. Conforme foi observado na introdução, não é o objetivo deste texto abordar o tema em uma perspectiva analítica que destaca o ambiente internacional de interação dos estados.

19 Conforme Chang (2009), a Organização Mundial do Comércio também tem contribuído para reforçar a manutenção da estrutura produtiva tradicional das economias primário-exportadoras. Daí as críticas ao "assistencialismo".
\end{abstract}

\section{Referencias}

CHANG, H-J. State, institutions and structural change. Structural Change and Economic Dynamics, Cambridge-UK, v. 5, n. 2, pp. 293313, 1994.

CHANG, H-J. The economics and politics of regulation. Cambridge Journal of Economics, v, 21, p. 703-729, 1997 .

CHANG, H-J. An institutionalist perspective on the role of the state - towards an institutionalist political economy. In: BURLAMAQUI, L.; CASTRO, A. \& CHANG, H-J. (Eds.). Institutions and the Role of the State. Edward Elgar. First Draft: October 1997b.

CHANG, H-J. The economic theory of developmental state. In: WOO-COMINGS, M. (Ed.). The developmental state. Ithaca and London: Cornell University Press, 1999, pp. 182-199.

CHANG, H-J. Breaking the mould: an institutionalist political economy alternative to the neoliberal theory of the market and the state. Social Policy and Development Programme. UNRISD Paper n. 6, may 2001. Disponivel em: https://bit.ly/3iBD88q. Acesso em: 17 mar. 2020.

CHANG, H-J. Chutando a escada: a estratégia do desenvolvimento em perspectiva histórica. São Paulo: UNESP, $2004 a$.
CHANG, H-J. State, institutions and structural change. In: CHANG, H-J. Globalisation, economic development and the role of the state. London and New York: Zed Books, 2004b, pp. 45-74.

CHANG, H-J. An institutionalist perspective on the role of the state: towards an institutionalist political economy. In: CHANG, H-J. Globalisation, economic development and the role of the state. London and New York: Zed Books, 2004c. pp. 75-103.

CHANG, H-J. Understanding the relationship between institutions and economic development - some key theoretical issues. In: CHANG, H-J. (Ed.). Institutional change and economic development. New York: United Nations University Press, 2007, pp. 17-33. CHANG, H-J. Hamlet without the prince of Denmark: how development has disappeared from today's 'development' discourse. Forthcoming (2010) In: S. Khan \& J. Christiansen (Eds.). Towards New Developmentalism: Market as Means rather than Master. Routledge, Abingdon. 15 February 2009a version.

CHANG, H-J. Maus samaritanos: o mito do livre-comércio e a história secreta do capitalismo. Rio de Janeiro: Elsevier, 2009b. 
CHANG, H-J. Institutional and economic development: theory, policy and history. Journal of Institutional Economics, v. 7, n.4, p. 473-498, 2011.

CHANG, H-J. \& ANDREONI, A. Institutions and the process of industrialisation: towards a theory of social capability development. In: NISSANKE, M. \& OCAMPO, J. A. (Eds.). The palgrave handbook of development economics: critical reflections on globalisation and development. Switzerland: Palgrave Macmillan, 2019. pp. 422-439

CHANG, H.-J. \& EVANS, P. The Role of Institutions in Economic Change. In: DYMSKI, G. and DA PAULA, S. (Eds.). Reimagining Growth. London: Zed Press, 2005. pp. 99-129.

FREEMAN, C \& PEREZ, C. Structural Crises of Adjustment, Business Cycles and Investment Behaviour. In: DOSI, G. et al. (Eds.). Technical Change and Economic Theory. London: Francis Pinter, 1988.

FRIEDMAN, M. Capitalismo e liberdade. Rio de Janeiro: Nova Cultural, 1985.

HODGSON, G. M. Downward causation some second thoughts. Watford (UK). Disponivel em: https://bit.ly/3kZkAln. Acesso em: ago. 2019.
HODGSON, G. M. Institutions and individuals: interaction and evolution. Organization Studies, Thousand Oaks (USA), v. 28, n. 1, p. 95-116, 2007.

LIST, G. F. Sistema Nacional de economia política. São Paulo: Nova cultural, 1989.

MAZZUCATO, M. O Estado empreendedor: desmascarando o mito do setor público vs. setor privado. São Paulo: Portfolio-Penguin, 2014.

NORTH, D. C. Institutions, institutional change and economic performance. Cambridge: Cambridge University Press, 1990.

NORTH, D. C. Institutions. The Journal of Economic Perspective, v. 5, n. 1, pp. 97-112, winter 1991.

NORTH, D.C. Understanding the process of economic change. Princeton/Oxford: Princeton University Press, 2005

NORTH, D., WALLIS, J. \& WEINGAST, B. Violence and Social Orders: A Conceptual Framework for Interpreting Recorded Human History. Cambridge: Cambridge University Press, 2009.

PÉREZ, C. Revoluciones tecnológicas y capital financiero: la dinâmica de las grandes burbujas financieras y las épocas de bonanza. México: Siglo XXI, 2004.

WILLIAMSON, O. E. Las instituciones económicas del capitalismo. México: FCE, 1989.

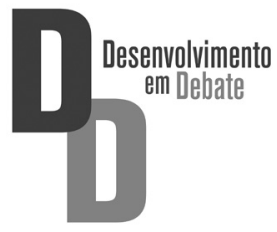

